\title{
NOVEL DECISION MODEL FOR DELIVERING SUSTAINABLE INFRASTRUCTURE SOLUTIONS - AN AUSTRALIAN CASE STUDY
}

\author{
K. MENEY \& L. PANTELIC \\ Syrinx Environmental PL, Australia.
}

\begin{abstract}
Conventional approaches to water supply and wastewater treatment in regional towns globally are failing due to population growth and resource pressure, combined with prohibitive costs of infrastructure upgrades. However, there are complexities associated with implementing sustainable infrastructure solutions, and a need to simplify the decision making process to equally compare alternatives to business-as-usual solutions. The aim of this study was to develop a model which could assist in delivering sustainable infrastructure solutions in regional towns (and elsewhere) to facilitate growth and/or reduce the burden on limited resources. The developed model (Sustainable Infrastructure Decision Model, SIDM ${ }^{\odot}$ ) ultimately organises intelligent inputs (from expert stakeholders and quantitative calculations) systematically and holistically in order to compare relative impacts, risks, costs, and benefits of varying solutions. In this sense, it deviates both from the 'black box' designs of many other sustainability tools, which requires trust of hidden data and formulas and from heuristic approaches that often 'set up' a subjective game of bias between stakeholders. Rather, SIDM $^{\odot}$ is based on a transdisciplinary system approach which facilitates informed decisions in a transparent manner. It links water, wastewater, energy, and waste (resource flows) along with stakeholders (consumers, producers), the receiving environment (receptors), and governing systems (managers, politicians, regulators, financers). Key to the approach is the use of local context analysis as a 'design' driver, along with equal consideration of stakeholder intent, capacity, and commitment. The model also includes an economic analysis and risk-based evaluation process to ensure that the preferred solution is optimised to the environmental, social, economic, and political setting of a particular town. The $\mathrm{SIDM}^{\odot}$ model was applied to a rapidly growing Australian township (Hopetoun) with complex resource and infrastructure constraints, which is described in this paper as a case study. Use of SIDM $^{\odot}$ resulted in an agreed decentralised solution which was approximately half of the cost of a conventional solution, with considerable water and energy savings and unanimous stakeholder support. Since this project, $\mathrm{SIDM}^{\odot}$ has been applied to other regional towns and urban developments in Australia.
\end{abstract}

Keywords: Energy, multicriteria analysis, sustainability decision model, sustainable infrastructure, wastewater, water.

\section{INTRODUCTION}

Sustainability as a concept for developing alternative solutions to human problems is not new by any means; however the take-up of the non-conventional is always met with a range of impediments. Decentralised treatment and/or management systems, the use of recycled water for non-potable uses, household based technologies for reducing environmental footprints, and alternative technologies for wastewater treatment, for instance, have challenged the traditional service models over the past 20 years at least in most developed countries. In spite of efforts to the contrary, implementing change and working towards integrated resource management solutions have proven to be difficult, even when policy changes support alternative approaches to water, energy, and waste infrastructure [1-6]. In Australia, recent pressures to 'shift' to sustainable infrastructure planning has predominantly been driven by limited resources, ageing infrastructure, drying climate, and the escalating costs of traditional solutions. However, it is also being driven by an increasing awareness 
that a change to responsible resource management is a social, environmental, and economic imperative [7-9]. As with elsewhere, this has been followed by a plethora of modelling and decision support tools $[10-16,17]$. One of the first frameworks developed to guide sustainable water planning/decision making in Australia was made by the Water Services Association of Australia (WSAA) and this is now an accepted approach for the water industry [18]. At this point in time however, comprehensive tools encompassing water, energy, wastewater, and transport are scarce in the published literature.

In spite of the existing tools, and in some instances good outcomes [18], the default to businessas-usual appears strong, and therefore the major barriers and issues do not appear to have been fully addressed. Impediments to sustainable infrastructure provision include a range of real and perceived factors (see [19] for a survey), which might be grouped as 'structural' and 'functional'. Structural impediments may include: i) lack of or onerous regulatory procedures, ii) use of standard approaches to cost evaluation (rather than systems analysis approaches that include externalities), iii) fixed formulas for delivery of services that are by nature inflexible, and iv) lack of an appropriate decision process that can accommodate a wide range of stakeholder groups. Functional impediments often include: i) real or perceived risks associated with adopting different technologies and management systems, ii) perceptions of 'new' or 'alternative' being 'second-best', and iii) inertia.

Structural impediments may be summed up as 'institutional change' phenomena, and functional impediments as 'individual change' phenomena. It is the structural impediments that so far, have largely prevented smooth progression of alternative infrastructure solutions in regional towns across Australia, and this appears to be similar in other countries [20,21]. Focusing on water management, in spite of the fact that the WSAA Framework was published in early 2008, very few wastewater reuse schemes or alternatives to business-as-usual have been developed within Australia since that time, with most of the (relatively few) larger wastewater recycling schemes pre-dating that framework [22,23]. Some projects that have been considered to be blocked due to functional impediments in retrospect can be argued to be due to a failure of the community engagement process undertaken by the relevant institutions and/or lack of bipartisan institutional support, e.g. the case of the Toowoomba water recycling project in Queensland [22,24].

The development of an integrated and streamlined decision framework is considered by the authors to be pivotal to addressing both structural and functional impediments across all resource streams. This inherently requires a tool to address the complexities associated with evaluating alternative solutions and delivery models against conventional infrastructure options (i.e. allow for equal footing comparison, or 'apples for apples') as well as a process for engaging a multiplicity of government, private, and community groups involved in alternative infrastructure projects at large scale. Because of the complex array of multiple and interacting temporal and spatial factors involved in sustainability analysis, such a tool must necessarily be comprehensive, will require expert assessments, but must also be straightforward enough to 'communicate' to a broad group of stakeholders and users.

While there are a plethora of decision tools used in sustainable development $[11,25,26]$, one that is focused on integrated resource management within specific local settings is needed to deliver a change towards a sustainable infrastructure culture. A successful decision approach must address governance challenges, as well as those to do with technical uncertainty and risk, and must be able to deal with uncertain futures. This paper details a systems approach taken for developing a fullstakeholder-supported alternative option for water, wastewater, and energy, using a regional town case study site in Hopetoun, Western Australia (WA). 


\section{MODEL DEVELOPMENT}

\subsection{Methodology}

A modified Analytical Hierarchy Process $[17,27]$ was adopted as an approach to the development of the sustainable infrastructure decision model $\left(\mathrm{SIDM}^{\odot}\right)$. The process involved structuring multiple choice criteria into a hierarchy based on their relative importance (critical, essential, and beneficial criteria), assessing and comparing alternatives for each criterion, and determining an overall ranking of the alternatives. Multiple choice criteria were developed based on first defining globally agreed sustainability principles, defining evaluation categories (environment, public health, socio-cultural, etc. - see Fig. 1), and defining targets specific to the project based on stakeholder objectives as determined via a stakeholder consultation process. Evaluation of each criterion requires synthesis and in some cases gathering of local information. Normally this would include data obtained from existing environmental impact assessments, social studies, and resource modelling studies.

In order to ensure rigor in the evaluation of criteria, inter-item reliability was used to test single concepts. In addition, checks for criterion related validity were built into the tool via incorporating a series of mostly quantitative measures for each criterion; these measures were chosen to best indicate whether a specific criterion was achieved or not.

The sustainability evaluation includes an economic assessment tool, incorporating conventional net present value (NPV) costings modified to include externalities. The economic assessment is based on a life cycle assessment (LCA) method using the principles of total cost analysis (TCA) [28]. As such, it includes direct project costs (capital and operating, or Type I and Type II costs), contingent risks (routine incidence allowances and overheads, Type III costs), intangible costs (i.e. those internal to the utility such as loss of reputation, customer loyalty, Type IV costs), and externalities (i.e. potential future costs associated with external impacts such as damages to environmental and human health, Type V costs). LCA is a growing research field and there are now many studies that have attempted cost-benefit assessments of a range of infrastructure initiatives at a large scale, including monetisation of nutrient emissions [29-31]. The SIDM ${ }^{\odot}$ externality assessment is tailored to the context of scale (local or regional infrastructure schemes), the existing regulatory framework, and to the actual costs of environmental degradation borne by external groups over and above regulatory compliance activities, in response to community expectations.

\subsection{The model}

The components of the $\mathrm{SIDM}^{\odot}$ model are shown in Fig. 1. The model contains four platforms (local context, planning, design, and management, which in effect represent sequential project phases) within which there are 17 categories relevant to these platforms (Table 1). The model comprises 84 criteria and 67 subcriteria relevant to each category. The criteria are fixed components of the model, although in certain projects some criteria may not be applicable and these would be scored as such. Additional subcriteria can be added on a project by project basis to enable tailoring of the model to specific settings (e.g. adding additional beneficial criteria), and measures can be modified to reflect specific projects or specific targets.

The model requires users to generate the targets which form the basis of the scoring system. Targets are therefore a variable input, and can be either determined for each project (via specific studies) or may use default national or state targets where these exist. For example, a willingness to pay criterion requires determining an acceptable capital and/or operating cost for a particular solution, 


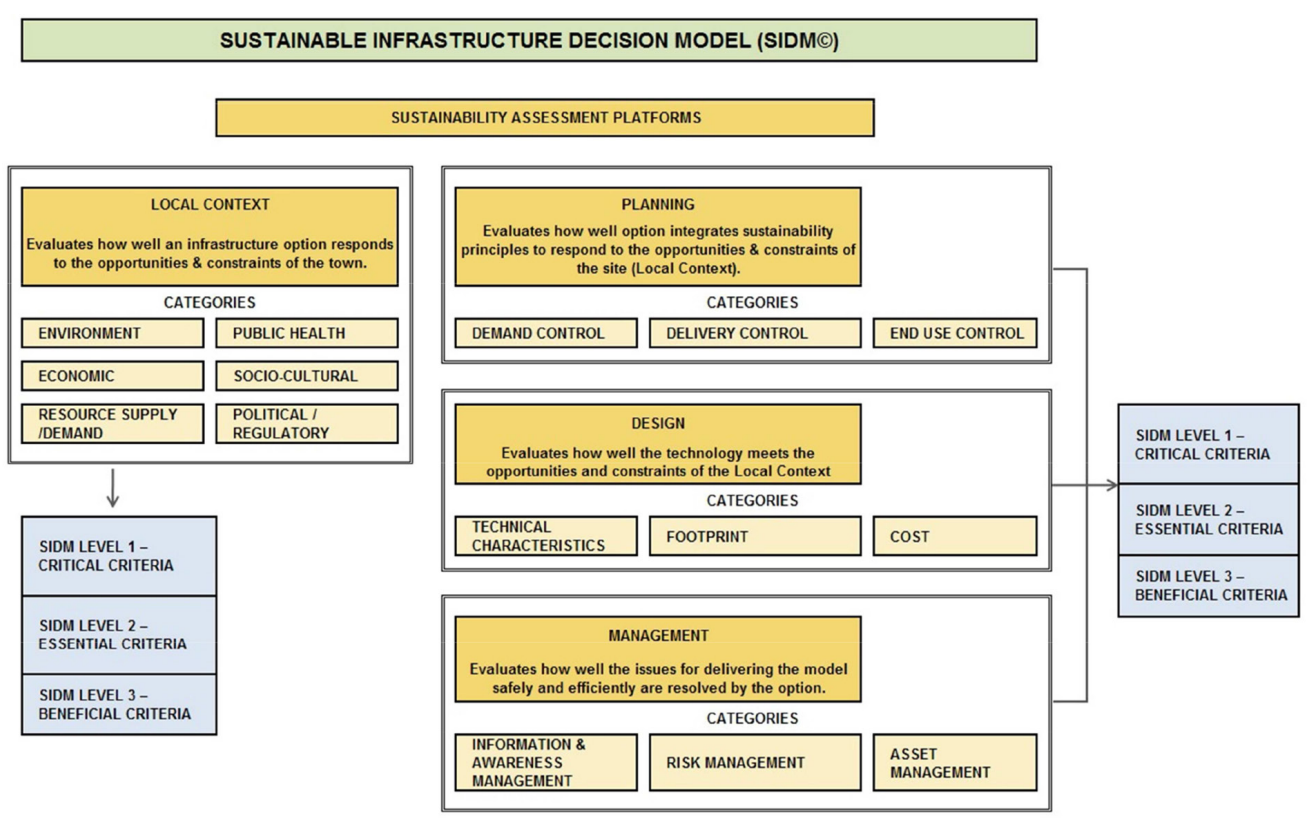

Figure 1: Schematic of the $\operatorname{SIDM}^{\odot}$ model.

which in most cases will be determined by the range of current cost profiles for essential services in similar regional towns. A sustainable infrastructure option that exceeds the acceptable cost target would score negatively for this criterion, for example.

Ahead of the evaluation tool, proponents must input data to a series of workbooks as follows: i) greenhouse gas (GHG) and nutrient balance calculations, ii) water and energy balance, iii) waste cycle balance, iv) bill of quantities and planning level costs, v) environmental externality costs, vi) summary data synthesising risk, constraint, and opportunity outcomes from environmental investigations, social and community surveys, and the regulatory and stakeholder consultation process. The model does not prescribe the use of particular modelling/analytical tools, but instead allows the user to utilise the most appropriate tool and/or tools already adopted as preferred by clients, experts, or regulatory authorities.

The model allows for progressive inputs (i.e. it can be populated sequentially by different groups according to their expertise and/or information availability) and provides percentage completion indices to track progress. Once all of the information is synthesised, the actual inputs to the model and evaluation can in most cases be done in a day's workshop session. This is usually the preferred method for projects which often have many and varied government and private entities responsible for delivering infrastructure services in existing and new towns or developments.

$\mathrm{SIDM}^{\odot}$ is intended to be used both as a design and evaluation tool. As a design tool, it i) guides the design of sustainable infrastructure solutions, ii) can be used as a progress check to assess the level of completion of a project, iii) highlights gaps in the existing information sets, and iv) essentially provides the scope of work required to advance the design process. As an evaluation tool it can act both as a quick diagnostic tool, to check whether or not a solution has major flaws or is generally acceptable, and as a detailed evaluation tool where various options can be compared in detail in order to establish a preferred solution. 
Table 1: Sustainability platforms and categories included in $\operatorname{SIDM}^{\oplus}$ model.

\begin{tabular}{ll}
\hline Sustainability platforms & Sustainability categories \\
\hline Local context & Environmental \\
& Public heath \\
Socio-cultural & Economic \\
& Political and regulatory \\
& Resource demand and supply \\
Planning & Stakeholder involvement and acceptance \\
& Source control \\
& Demand control \\
& Delivery control \\
End-use control \\
Design & Technical characteristics \\
& Footprint \\
Management & Cost \\
& Risk management \\
& Information management and awareness \\
& Asset management \\
\hline
\end{tabular}

The model has the capacity to evaluate the water, wastewater, energy, and transport components of the integrated resource management solution in parallel, or alternatively can be used in the design and assessment of individual resource solutions (e.g. wastewater only) or even individual technologies (e.g. wastewater treatment technology).

\subsection{Associated tools and other inputs}

Data inputs to the $\operatorname{SIDM}^{\odot}$ model (e.g. water and energy use, pollutant emissions, costs) can be generated using any number of credible external tools and local information sets. This means SIDM ${ }^{\odot}$ has the flexibility to cater for improvements in external datasets as they become more reliable and standardised, without the need to upgrade the model itself.

A specific economic tool was developed to complement the decision process as a separate module. This was undertaken to address the type and range of specific technologies used in sustainable infrastructure planning and design as well as the requirement of SIDM $^{\odot}$ to assess externality costs in addition to the more standard NPV analysis. The tool enables rapid selection from a range of in-built technologies, (as well as allowing addition of others), has default values for discount rates, contingencies, operating costs, capital escalations, etc., and a variable operating risk input so that 'new' or untested technologies can be differentiated from 'proven' technologies for example. The NPV analysis can be set for any period of time. Decisions on the ascribed risks and escalations can be made on a case-by-case basis in consultation with service providers and other stakeholders. The tool also enables the apportioning of costs and revenue streams to optimise asset management. 


\subsection{Criteria}

Criteria are ranked into critical (Level 1 - qualitative assessment), and essential and beneficial criteria (Level 2 - quantitative assessment). The need for additional criteria or modification of measures can be determined via a workshop process with all stakeholders (e.g. regulators, developers, service providers, community) which assists in the acceptance of the outcomes generated ultimately by the 'model'.

Critical criteria are those that describe the minimal project requirements that options must satisfy in order to be considered appropriate for further evaluation. In total there are 28 critical criteria, distributed amongst the sustainability categories shown in Table 1. Failure to meet any critical criterion is considered a 'fatal flaw' and the proposed option would not proceed further until changes are made sufficient to pass this criterion. For example, a critical criterion for a regional town may be 'no further groundwater abstraction where this is over-allocated'. In most cases, critical (and essential criteria) are based on existing regulatory requirements.

In the Level 2 assessment, each infrastructure option is quantitatively evaluated against the local context, planning, design, and management platforms for essential and beneficial criteria. Essential criteria are those that are considered necessary for meeting the service provision sustainably. Beneficial criteria are the 'value-adds' provided by a given option (e.g. biodiversity enhancement, indirect economic opportunities).

Examples of the essential assessment criteria and measures are shown below:

1. Local Context Platform - Environmental Category:

Criterion: Minimisation of negative impacts.

Subcriterion: Prevention of discharge of low quality water to groundwater and surface waters.

Measure: Quality of discharge water must not be lower than quality of receiving environment; compare expected water quality data with receiving environment data.

2. Local Context Platform - Socio-cultural Category:

Criterion: Acceptability to community.

Subcriterion: Solution accepted by all user groups within the town.

Measure: $\quad$ A YES answer would mean acceptance of $>90 \%$ of the representative community groups; this should be obtained during the community consultation process.

3. Management Platform - Risk Management Category:

Criterion: Risk profile acceptable to all stakeholder groups.

Subcriterion: The risk management framework must be acceptable to the service providers managing, or likely to manage, the scheme.

Measure: $\quad$ A YES answer means a consultation process and business case has been undertaken and agreed with all service providers.

\subsection{Scoring}

Critical criteria are assessed on a pass/fail basis, which means that an entire project can be halted if one of these criteria is not met ( 28 in total). Once all critical criteria are met, essential criteria are scored (equally for all criteria), and these scores form the initial evaluation outputs. The beneficial criteria are also scored but are reported separately and used to differentiate between solutions that are closely aligned. Scoring for these essential and beneficial criteria is done in quantitative form 
as: +1 if the criterion is met or -1 if the criterion is not met. If the criterion is not relevant (not applicable) to the resource type (water, wastewater), the criterion is scored 0.

The model scores each option against the sustainability criteria within each category, such that separate scores are generated for the different platforms (local context, planning, design, and management), for each category within these platforms and for each resource type (i.e. water, wastewater, waste, energy; refer to Fig. 1). Scores are not weighted by consensus (which is a common multicriteria analysis (MCA) approach) to avoid subjectivity and to reflect the reality that consensus groups are normally too few and too skewed to be statistically representative, and to avoid conflicts between statutory priorities and personal preferences [32,33]. However, a form of weighting is achieved via the prioritisation of criteria, i.e. into critical, essential, and beneficial criteria.

A score is awarded based on the available information (scores for essential and beneficial criteria are either negative or positive where information is known, with no score awarded where information has not been provided or is uncertain). In this manner, the scores are progressively updated as the project develops. While ideally all uncertainties should progressively be removed by addressing the information gaps identified, the model is flexible such that stakeholders can progress with the evaluation process, and either revisit these uncertainties at a later point in time, or if addressing these uncertainties will not materially affect the emerging 'winner', then agree to have these addressed in design and approval stages for instance.

It should be noted that there is no consensus on reducing subjectivity in weighting approaches to multicriteria assessments, with some arguing that the equal weighting approach is also subjective [34]. While some element of subjectivity is inevitable, equal weighting was considered essential in providing rigour to SIDM $^{\odot}$ due to the complexity and multiplicity of the sustainability categories and potential impacts. That is, a robust ranking process would require a plethora of equally able and informed professionals, and equal representation of skill sets and interests to negotiate a hierarchy (which ultimately requires conversion from a position or compromise). This is clearly a time consuming process and not feasible for most sustainable infrastructure projects, and diverts the focus and time away from the project goal, i.e. to deliver the optimal infrastructure solution.

\section{APPLICATION OF THE SIDM ${ }^{\odot}$ PROCESS TO A CASE STUDY}

\subsection{Case study site}

Hopetoun is a small rural coastal town in southeast WA which, like many other regional Australian towns, experienced extensive expansion in 2006/2007 due to the economic boom from mineral exploration and mining activities. Specifically, growth was connected to the development of the nearby BHP Billiton Ravensthorpe Nickel Operation (BHPB RNO), and associated housing and servicing needs for the projected residential workforce.

To service this growth, upgrades in infrastructure were required, including provision of wastewater services, water supply, and power supply. A number of challenges, including uncertain population projections and excessive forecast costs for providing conventional infrastructure upgrades, caused delays in resolving infrastructure issues, resulting in an effective suspension of development activity. Limitations of the groundwater supply were a key constraint along with capacity thresholds for power and the existing wastewater system. These factors were the impetus for this study, which was intended to both derive an alternative sustainable solution for this town, as well as identify the barriers to alternative infrastructure planning within the broader State. 


\subsection{Option development}

The study was overseen by a multiagency group comprising government, mining, and community stakeholders established to ensure a collaborative and open process. This group assisted in navigating the current regulatory setting, distilling the particular objectives and drivers of each of the decision makers (including service providers), and agreeing on appropriate criteria and specific targets to assess technical, planning, and management components of a given project.

The required datasets used to develop options and undertake the $\mathrm{SIDM}^{\odot}$ assessment process were obtained from the local government authority, BHPB RNO, and various State agencies. Information sets covered social attitude surveys, vegetation studies, rainfall \& evaporation data, groundwater studies, population projections, and demographic profiles. Economic data, including actual sunk costs, target per household costs, etc. was obtained from the local utility providers.

Three infrastructure Option Packages were developed for Hopetoun. These included the 'Base Case' or 'business-as-usual' scenario (Option Package 1), as well as two alternative solutions (Option Packages 2 and 3). A key driver of the alternatives was to meet equity in service provision for both the existing town (to enable subdivision) and new housing expansion areas (not addressed by the Base Case). A key design factor was the need to incorporate the existing infrastructure (either physically or as a sunk cost component).

The 'Base Case' (centralised option) solution included:

- Wastewater: A centralised reticulated sewage system (servicing 1,177 lots) with an existing facultative lagoon system (with mechanically aerated ponds, evaporation ponds and a storage dam) located approximately $5 \mathrm{~km}$ out of the town centre. Disposal is via evaporation and for irrigation of the golf course. The Base Case proposed extension of the gravity and pressure main system to the new housing developments only. This scheme also included an option for future ocean outfall disposal.

- Water: Expansion of the potable groundwater supply network (requiring desalination and softening and servicing 1,792 lots) which was planned to be replaced with a seawater desalination plant as the water demand exceeds the groundwater supply. The scheme does not include any reuse options.

- Energy: An existing hybrid wind/diesel power supply, which was to be upgraded by adding diesel generators.

Option Package 2 (semi-decentralised option) included:

- Wastewater: A cluster based approach to the collection, treatment, \& redistribution of treated wastewater servicing 1,850 lots that included: i) full reticulated collection of wastewater from all properties (12.6 km pressure and gravity pipework), with liquids-only collection from existing houses (solids retained in septic systems), ii) treatment in cluster ultrafiltration Membrane Bioreactors (MBR) with disinfection for indoor reuse, iii) third pipe system to households, industrial, and commercial/retail lots and Public Open Space (POS) $(9 \mathrm{~km})$, iv) storage of excess treated effluent (70 ML winter storage) in existing ponds $5 \mathrm{~km}$ from town.

- Water: A hybrid household/centralised water supply scheme (1,792 serviced lots) with water recycling initiatives is as follows: i) installation of water efficient fixtures and fittings to new and existing houses, ii) internal potable demand met by on-lot harvested rainwater (5 kL tanks) supplemented with bore water from the existing groundwater supply, iii) non-potable internal uses (toilet and cold water to laundry) and irrigation demand (gardens, POS) met by treated wastewater. 
- Energy: A hybrid household/centralised energy supply with small wind turbines or household photovoltaics (PVs) (1,792 serviced lots). A range of demand management measures were included such as i) Distribution Frequency Load Shedding (DFLS) installed in new houses and commercial/retail buildings for peak load management, ii) smart meters and smart grid system on all houses to enable centralised shut-down of appliances during demand overload periods.

Option Package 3 (decentralised option) included:

- Wastewater: A cluster based approach to the collection, treatment \& redistribution system servicing 1,850 lots, that included: i) on-site greywater treatment and reuse, ii) collection and conveyance of blackwater and greywater overflow in a reticulated sewage network (12.6 km pressure and gravity pipework) with liquids only collection from existing houses (solids retained in septic systems), iii) treatment in cluster membrane bioreactors (ultrafiltration MBR) with disinfection for indoor reuse, iv) small third pipe system for return of high level treated blackwater for POS irrigation, and limited commercial/industrial internal reuse $(7.2 \mathrm{~km}, \mathrm{v})$ storage of excess treated effluent (53 ML winter storage) in existing ponds $5 \mathrm{~km}$ from town.

- Water: A hybrid household/centralised water supply scheme (1,792 serviced lots) that included i) installation of water efficient fixtures and fittings to new and existing houses, ii) internal water demand (except toilets) met by rainwater and supplementary groundwater, iii) toilet demand and household irrigation met by on-site greywater reuse, iv) POS irrigation met by treated blackwater.

- Energy: As per Option Package 2.

- Both alternative options were modular in nature allowing for a staged roll-out in concert with population growth. The alternative options allowed the selection of a range of technology types or management measures to be combined to provide the desired outcomes.

\subsection{Sustainability testing $\left(\operatorname{SIDM}^{\odot}\right)$ outcomes}

The results of the $\mathrm{SIDM}^{\odot}$ scoring of the three Option Packages across local context, planning, design, and management sustainability platforms (see Table 1) are given in Fig. 2.

The overall results of the combined sustainability criteria used to assess each option under water, wastewater, and energy categories are shown in Fig. 3. This graph 'lumps' the 69 essential criteria (and subcriteria) applied in the multivariate analysis to 17 categories within four sustainability platforms.

Both alternative options scored better than the Base Case option for water, wastewater, and energy. Option 2 scored slightly higher than Option 3 for wastewater (Fig. 2), and was determined the preferred option since there were no 'fatal flaw' barriers. Option 3 had proposed on-lot greywater treatment and reuse which scored poorly due to asset management and regulatory risk issues at the time.

\subsection{NPV and externality cost evaluation}

\subsubsection{NPV assessment}

In this study, cost comparisons were done on preliminary (planning level) estimates for many infrastructure components, with large contingencies (45\%) included for 'new' technologies, which was agreed as a means of capturing cost uncertainties. Overheads, contingency costs, and intangible 


\begin{tabular}{l|l|l|l|}
\hline \multicolumn{5}{l}{ WASTEWATER } \\
\begin{tabular}{|l|l|l|l|}
\hline & OPTION & OPTION & OPTION \\
PACKAGE 1 & PACKAGE 2 & PACKAGE 3 \\
\hline LOCAL CONTEXT & $47 \%$ & $97 \%$ & $90 \%$ \\
PLANNING & $25 \%$ & $100 \%$ & $100 \%$ \\
DESIGN & $50 \%$ & $80 \%$ & $67 \%$ \\
MANAGEMENT & $33 \%$ & $100 \%$ & $100 \%$ \\
\hline
\end{tabular}
\end{tabular}

WATER
\begin{tabular}{|l|l|l|l|}
\hline & OPTION & OPTION & OPTION \\
PACKAGE 1 & PACKAGE 2 & PACKAGE 3 \\
\hline LOCAL CONTEXT & $52 \%$ & $91 \%$ & $91 \%$ \\
PLANNING & $33 \%$ & $100 \%$ & $100 \%$ \\
DESIGN & $0 \%$ & $100 \%$ & $100 \%$ \\
MANAGEMENT & $25 \%$ & $80 \%$ & $80 \%$ \\
\hline
\end{tabular}

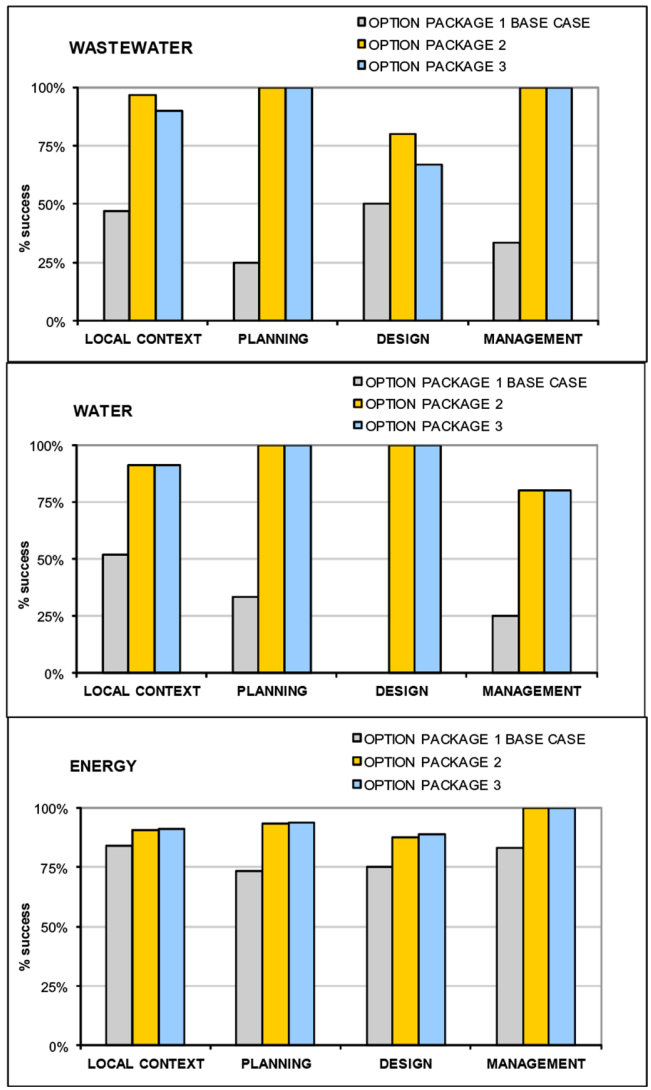

Figure 2: Outcomes of sustainability testing of different infrastructure solutions developed for Hopetoun using the SIDM $^{\odot}$ model.

ENERGY
\begin{tabular}{|l|l|l|l|}
\hline & $\begin{array}{l}\text { OPTION } \\
\text { PACKAGE 1 }\end{array}$ & $\begin{array}{l}\text { OPTION } \\
\text { PACKAGE 2 }\end{array}$ & $\begin{array}{l}\text { OPTION } \\
\text { PACKAGE 3 }\end{array}$ \\
\hline LOCAL CONTEXT & $84 \%$ & $91 \%$ & $91 \%$ \\
PLANNING & $73 \%$ & $93 \%$ & $94 \%$ \\
DESIGN & $75 \%$ & $88 \%$ & $89 \%$ \\
MANAGEMENT & $83 \%$ & $100 \%$ & $100 \%$ \\
\hline
\end{tabular}

costs were included in profit and overhead margins. Sunken infrastructure costs were included in this analysis, since assets (hybrid wind-diesel turbines, existing wastewater lagoon, pipework, etc.) were not at the end of their asset life. This clearly disadvantaged full decentralised schemes.

The resulting economic analysis showed Options Package 2 was the preferred option. The NPV cost for Option 2 was around $\$ 60$ million compared with $\$ 134$ million for the Base Case, for the combined water, wastewater, and power infrastructure for an estimated 3,500 population scenario. Water costs were; $\$ 24$ vs. \$61 million, wastewater \$26 vs. \$23 million, and power \$14 vs. \$48 million for Option 2 and the Base Case, respectively.

The cost for the desalination plant and the required upgrade of the existing hybrid wind/diesel system and high operating costs due to diesel fuel use were the two main contributors to the very high total cost of the Base Case. The difference in NPV costs between the two alternative options varied marginally $(10-15 \%)$, predominantly reflecting the similarities in water and energy components between Options 2 and 3. Option 3 was found to be a less favorable economic solution on an indicative cost basis, mainly due to the high costs of on-lot greywater systems but also because of the large sunken infrastructure costs which penalised a fully decentralised solution in Hopetoun. 


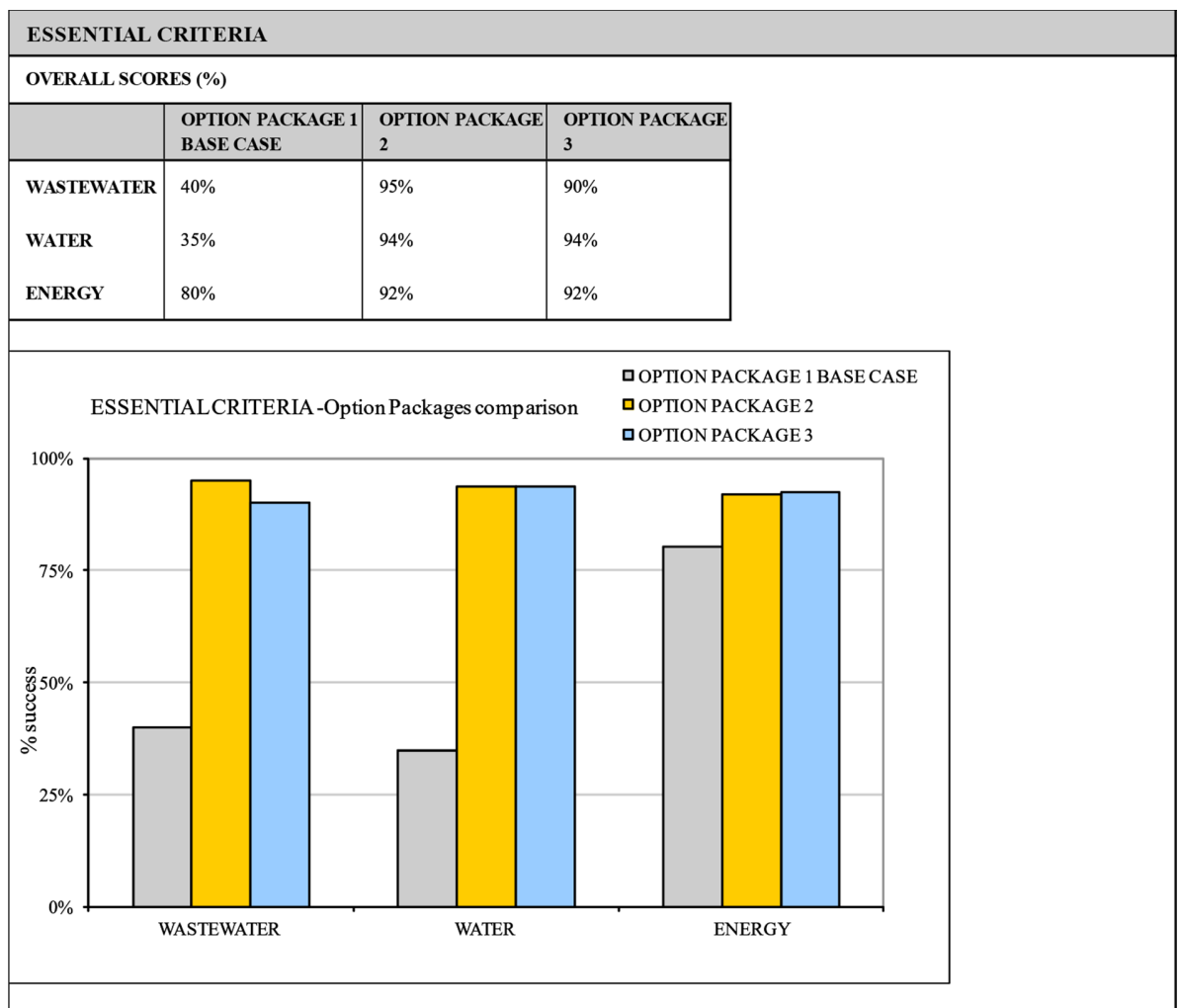

Figure 3: Overall scores of sustainability testing of different infrastructure solutions developed for Hopetoun using the $\operatorname{SIDM}^{\odot}$ model.

Excess treated wastewater in this Option still requires conveyance and storage, and the pipe lengths and pump costs are only marginally reduced over Option 2.

\subsubsection{Externalities}

The impact categories were limited to those relevant to the Hopetoun scale (i.e. small town local infrastructure scheme), and those typically experienced by the utility providers at similar sites. Thus, the externalities were i) GHG emissions, which were calculated for each developed option using the National Greenhouse Accounts method [35], ii) opportunity costs associated with nutrient losses, since these are tangible costs already monetised within the Australian market (i.e. unit cost of nitrogen fertilisers), iii) environmental damages, whether borne directly by utility providers as claims and fines (since this indirectly cascades through to higher societal charges) or by broader society (external groups involved in environmental restoration or remediation) [28]. Costs for the latter were taken from utility-provided information on similar events (e.g. leakage repairs, costs per hectare of restoration for similar works), as well as restoration/remediation costs from the industry at the time.

Option 2 was also found to be economically superior to the Base Case in terms of externality costs related to operating environmental emissions (GHG and nutrients emissions) as well as impacts due to system failure. GHG arising from direct and indirect emissions as well as the embodied energy of 
the infrastructure elements was calculated for wastewater and water infrastructure components. Despite the incorporation of an energy-intense MBR plant into the Option 2 wastewater infrastructure, the Base Case GHG emission from the wastewater component was higher $\left(1,253 \mathrm{tCO}_{2}\right.$-e/year compared to $1,045 \mathrm{tCO}_{2}$-e/year for Option 2) mainly due to the high raw sewage pumping requirements (to evaporation pond and ocean discharge) and high direct emissions from the aeration pond. In terms of water infrastructure, emissions from the Base Case were calculated to be almost double those of Option 2 (693 tCO 2 -e/year compared to $381 \mathrm{tCO}_{2}$-e/year) primarily due to the high energy use of the proposed seawater desalination plant and higher pumping requirements for groundwater as a main water supply.

Although the overall GHG emissions for Option 2 were found to be $\sim 30 \%$ less than that of the Base Case, in a monetary sense the difference was not significant. Accounting for these costs showed an additional $\$ 140 \mathrm{k}$ over the 20-year period for the Base Case (conservatively measured at $\$ 23 /$ tonne with a $3 \%$ annual increase, in line with government recommendations at the time). Further, the addition of externality costs for energy would be more significant than for water and wastewater; this was not included in the overall costing (undertaken separately by the utility and data not made available). Note, it is likely that in the current political climate, both the unit cost and escalation were conservative over the full 20 -year period. For example, the carbon price was expected to change (decrease) from the 1st of July 2015 as a result of a transition from a fixed to a flexible price phase which was anticipated to be influenced by the EU carbon price (currently at \$10/tonne). The latest change in the Australian Government's position towards the regulation of emissions resulted in the abolishment of the carbon pricing mechanism from 1 July 2014.

Nutrient emissions were only considered for the wastewater infrastructure component of the proposed options; water and energy infrastructure components were considered not to cause any significant nutrient emissions. Only the cost of nutrient 'loss' was included in the economic analysis. This cost represents benefits of nutrient use as a function of the reduction of $\mathrm{N}$-fertiliser use. Although costs of nutrient loss did not represent a major component of the overall costs, both alternative options performed much better than the Base Case for this externality given they incorporated reuse

Table 2: Externalities from system failure - cost comparison between Base Case and Option Package 2.

\begin{tabular}{llrr}
\hline & & \multicolumn{2}{c}{ Annual cost } \\
\cline { 3 - 3 } $\begin{array}{l}\text { Environmental } \\
\text { end-point }\end{array}$ & Event & Base Case & $\begin{array}{c}\text { Alternative } \\
\text { options }\end{array}$ \\
\hline Wetlands \& vegetation & Biodiversity loss & $\$ 831,080$ & $\$ 0$ \\
Groundwater & Drinking catchment contamination & $\$ 216,000$ & $\$ 0$ \\
& Natural catchment contamination & $\$ 70,000$ & $\$ 78,000$ \\
Ocean \& surface water & Contamination of coastline & $\$ 90,000$ & $\$ 56,000$ \\
& Contamination of surface water & $\$ 250,000$ & $\$ 120,000$ \\
Soil & Sodicity & $\$ 16,000$ & $\$ 0$ \\
Total & & $\$ 1,500$ & $\$ 1,665$ \\
\hline
\end{tabular}

${ }^{1}$ Groundwater Dependent Ecosystems 
of treated effluent for irrigation. Note, other costs commonly considered in the analysis of nutrient emissions [29-31], were not included in this study since this was a local infrastructure project and regional assessment of impacts not relevant to the scale.

In terms of other externalities related to impacts from system failure, the results indicated that the offsets required for these Type 5 costs for the Base Case were more than five times that of Option 2 (Table 2). This analysis focused on the impacts to environmental health, public health, and recreational (socio-economic) impacts, which are some of the key impact types commonly considered when estimating the costs of externalities related to the service provision [36-38].

\subsection{Key benefits and barriers of the sustainable infrastructure solution}

\subsubsection{Benefits}

The key sustainability benefits of Option 2 were as follows:

- High level of resource conservation and reuse, through largely substituting the dependency on groundwater with rainwater, (which is reliable and well distributed in Hopetoun), and treated wastewater.

- Flexibility/adaptability in allowing for current innovative technologies, while also allowing capacity for components to change over time as necessary in response to further technology improvements.More than $60 \%$ reduction in groundwater demand, compared with the Base Case, which improves environmental flow provisions in line with the objectives of the State Water Strategy [39].

- A 30-50\% reduction in non-renewable energy demand through household small turbine or PVs and peak demand management, which defers the requirement for additional diesel generators to supplement the existing hybrid wind/diesel system, and a lower operating cost.

- Reduced energy demands by selection of off-peak systems and low energy components in water/ wastewater pumping and distibution systems. This helped avoid energy demand thresholds and cost escalations associated with deferring any major power upgrades.

- Met the community expectations in terms of equity of service provision and allowed for spin-off economic opportunities.

- Significantly lower capital and NPV cost compared with the Base Case.

- Significantly lower externality costs, particularly those associated with incident costs.

\subsubsection{Barriers}

While the SIDM ${ }^{\odot}$ model showed Option 2 was the preferred solution for infrastructure provision within Hopetoun, a raft of challenges for implementing this option were identified. These included asset management issues, political reluctance to adopt change, and an unequal scrutiny on technical aspects of business-as-usual versus any alternative options. Even with a strong business case favouring Option 2, some stakeholders were still indecisive, and took some time to work on internal processes before finally supporting the proposed solution. This eventual agreement amongst all stakeholders was achieved by the progressive working through of issues and identification of the necessary institutional changes needed to advance the alternative solutions.

The key barriers were found to be associated with entrenched institutional cultures and difficulties in implementing new asset management arrangements that do not accord with existing risk profiles and/or business objectives. These were as follows: 
- Resistance of existing service providers in the water and wastewater sector in adopting 'new' ways. For instance, changes to both technical and commercial arrangements are necessary for integrated service provision, which is preceived as difficult in organisations where resources are planned, managed, and delivered by different departments or utilities.

- Relatively new and still uncertain water and wastewater market for private operators, especially where existing State providers occur, due to 'government preference for government utilities' and 'old and proven' players.

- Confusion on how to deliver or participate in new asset management structures for delivering alternative infrastructure solutions, with a tendency towards high business risk aversion and a pattern of separating resources and infrastructure components (e.g. water supply separate from wastewater).

In the case of Hopetoun, these challenges were overcome by bringing together all stakeholders with their differing mandates, and working through the fundamental asset management challenges - i.e. who owns, who operates, where does the liability sit, who pays, who benefits? Ultimately, the solution for Hopetoun involved a mix of Shire, existing service providers, householders, and private providers taking varying own/operate/manage roles. Because of the proportionally higher per household costs on the scheme, (although total costs were approximately half), a higher rebate scheme (via a community subsidy process) was proposed to offset householder costs and ensure on-lot assets were installed and appropriately maintained. A staging plan ensured the risks and initial capital investment were minimised, such that population uncertainties were managed by growing infrastructure provision in line with, instead of ahead of, growth. Given the subsequent withdrawal of BHP Billiton from the locality due to falling nickel prices, the value of a modular infrastructure solution with staging flexibility in regional towns was reinforced.

\section{CONCLUSIONS}

This study successfully led to the development of a new sustainability decision tool $\left(\mathrm{SIDM}^{\odot}\right.$ ) to enable the development and evaluation of sustainable infrastructure options in regional towns or any urban growth area. Since the Hopetoun project, the model has been applied to many other regional towns, new urban greenfield subdivisions, and infill (brownfield) urban developments.

The beneficial characteristics of $\mathrm{SIDM}^{\odot}$ over most other models are as follows:

- Integration of requirements for water, wastewater, energy, and waste infrastructure in a holistic sense, instead of treating them in isolation.

- Equal weighting of sustainability categories (environmental, social-cultural, economic, political-regulatory, resource), within a hierarchy of critical, essential, and beneficial criteria, as opposed to averaged output from various and divergent categories.

- Integration of a qualitative matrix into a quantitative life cycle economic model, which accounts for capital cost, operating costs, and externalities in a multicomponent and multitiered analysis, allowing for varying discount factors.

The resultant model is integrated, objective, and transparent which enables decision making based on clear, comprehensive, and independent information sets. This forces the decision to be made objectively by accepting equal weighting of sustainability criteria within the three hierarchies (critical, essential, beneficial).

Because the model contains a significant stakeholder component to cover social, political, and regulatory criteria, it requires an ongoing engagement process with all stakeholder groups in order 
to complete the sustainability assessment. In this manner, $\mathrm{SIDM}^{\odot}$ provides a means of achieving a transdisciplinary process and facilitates an understanding of the individual drivers and barriers confronting various decision groups.

The model was tested in a regional town undergoing rapid growth and with constrained resource supply and inadequate water, wastewater, and power infrastructure servicing. The model was successful in achieving a unified agreement on a decentralised solution for this town, in spite of a wide range of stakeholder and service provider groups, a critical regulatory process, and a general reluctance of organisations to change given the expectation of onerous liabilities and the need to develop new procedures and practices.

A key requirement of sustainable infrastructure provision, and a major component of the SIDM ${ }^{\odot}$ tool, is the requirement for integrating resources when developing and evaluating infrastructure solutions. The Hopetoun case study showed that integration of water, wastewater, and energy infrastructure components in any context is complex, but necessary in delivering a sustainable outcome and essential for economic viability. However, if this is to become modus operandi for other regional towns and urban developments, there needs to be a fundamental shift in the way that water, wastewater, and energy are considered in the planning phase of projects.

Most of the barriers identified in this study are still common issues across Australia and most likely internationally, and will require major effort from the highest level of government to ensure the required changes are supported by policy and that this is effectively cascaded through to the delivery end of the service provider market. Significantly, rising concerns in the US with regard to ageing water infrastructure have spurred major policy reforms in sustainable water infrastructure (including a Sustainable Water Infrastructure Act of 2011), and this includes requirements for governments and other entities to remove or modify institutional barriers and practices that impede or prevent sustainable water resource management [21]. However, integrated resource policies are scarce, partly because government departments and programs are too compartmentalised to be effective in addressing many issues associated with sustainability.

Nonetheless, $\mathrm{SIDM}^{\odot}$ has proven to be a useful method of stepping through structural and functional impediments and delivering an agreed integrated sustainable infrastructure outcome for regional towns. The model has proven effective in identifying alternative solutions and ensuring these are considered from a sustainability perspective, rather than viewed in terms of the singular business models of conventional utility providers. Other requirements are likely to be necessary to ensure adoption of sustainable infrastructure solutions in Australia and globally. These will depend somewhat on the geographic, political, and economic context of an area, but will require effective competition policy, changes to economic valuations in government treasury departments so that externality costs (or full LCA costs) are reflected in project assessments, and consistent regulatory requirements to enforce global best practices and sustainable infrastructure solutions. All of these require time, political support, and in turn, financial impetus.

\section{ACKNOWLEDGEMENTS}

The authors would like to thank the stakeholders and participants in the Hopetoun project: LandCorp, Department of Water, Water Corporation, Horizon Power, Department of Industry and Infrastructure, Department of Health, BHP Billiton, and Shire of Ravensthorpe. Pracsys is acknowledged for co-developing the economic tool. The authors are grateful to Dr Peter Coombes (Chief Scientist, Office of Living Victoria), Dr Martin Anda (Murdoch University), Barton Williams (former Business Manager, Design \& Sustainability, LandCorp), and SGS Economics and Planning for peer review. 


\section{REFERENCES}

[1] Tchobanoglous, G., Darby, J., Ruppe, L. \& Leverenz, H., Decentralized wastewater management: challenges and opportunities for the twenty-first century. Water Science \& Technology: Water Supply, 4(1), pp. 95-102, 2004.

[2] Ho, G., Small water and wastewater systems: pathways to sustainable development? Water Science \& Technology, 48(11-12), pp. 7-14, 2003.

[3] Gardner, E.A., Some examples of water recycling in Australian urban environments: a step towards environmental sustainability. Water Supply, 3(4), pp. 21-31, 2003.

[4] Wilderer, P.A. \& Schreff, D., Decentralized and centralized wastewater management: a challenge for technology developers. Water Science \& Technology, 41(1), pp. 1-8, 2000.

[5] Livingston, D., Colebatch, H.K. \& Ashbolt, N.J., Institutional barriers to decentralised systems. Water, Journal of the Australian Water Association, 33(3), pp. 84-86, 2006.

[6] Livingston, D.J., Stenekes, N.A., Colebatch, H.K., Ashbolt, N.J. \& Waite, T.D., Water recycling and decentralised management: the policy and organisational challenges for innovative approaches. 2004 International Conference on Water Sensitive Urban Design, presented at International Conference on Water Sensitive Urban Design, Adelaide, 21-25 November, 2004.

[7] Syme, G.J. \& Nancarrow, B.E., Changing attitudes to urban water use and consumption (Chapter 33). Transitions: Pathways towards Sustainable Urban Development in Australia, ed. P.W. Newton, CSIRO Publishing Collingwood, pp. 509-519, 2008.

[8] Anderson, J., The environmental benefits of water recycling and reuse. Water Science and Technology: Water Supply, 3(4), pp. 1-10, 2003.

[9] Sharma, A.K., Cook, S. \& Chong, M.N., Monitoring and validation of decentralised water and wastewater systems for increased uptake. Water Science \& Technology, 67(11), pp. 25762581, 2013. doi: http://dx.doi.org/10.2166/wst.2013.168

[10] Wang, X.A., Proposal and application of the integrated benefit assessment model for urban water resources exploitation and utilization. Water Resources Management, 23, pp. 1171-1182, 2009.

[11] Makropoulos, C.K., Natsis, K., Liu, S., Mittas, K. \& Butler, D. Decision support for sustainable option selection in integrated urban water management. Environmental Modelling \& Software, 23(12), pp. 1448-1460, 2008. doi: http://dx.doi.org/10.1016/j.envsoft.2008.04.010

[12] Lim, S.-R., Suh, S., Kim, J.-H. \& Park, H.S., Urban water infrastructure optimization to reduce environmental impacts and costs. Journal of Environmental Management, 91(3), pp. 630-637, 2010. doi: http://dx.doi.org/10.1016/j.jenvman.2009.09.026

[13] Willuweit, L. \& O’Sullivan, J.J., A decision support tool for sustainable planning of urban water systems: presenting the dynamic urban water simulation model. Water Research, 47(20), pp. 7206-7220, 2013. doi: http://dx.doi.org/10.1016/j.watres.2013.09.060

[14] Schulz, M., Short, M.D. \& Peters, G.M., A streamlined sustainability assessment tool for improved decision making in the urban water industry. Integrated Environmental Assessment and Management, 8(1), pp. 183-193, 2012.

[15] Chen, Z., Ngo, H.H. \& Guo, W., A critical review on sustainability assessment of recycled water schemes. Sci Total Environ, 426, pp. 13-31, 2012. doi: http://dx.doi.org/10.1016/j.scitotenv.2012.03.055

[16] Marlow, D.R., Beale, D.J. \& Burn, S., A pathway to a more sustainable water sector: sustainability-based asset management. Water Science \& Technology, 61(5), pp. 1245-1255, 2010. doi: http://dx.doi.org/10.2166/wst.2010.043 
[17] Saaty, T.L., Decision Making for Leaders - The Analytic Hierarchy Process for Decisions in a Complex World, 3rd edn., RWS Publications: USA, 2001.

[18] Water Services Association of Australia, Guide to Demand Management: The Urban Water Planning Framework, WSAA Occasional Paper No.18, February 2008.

[19] Brown, R., Farrelly, M. \& Keath, N., Summary Report: Perceptions of Institutional Drivers and Barriers to Sustainable Urban Water Management in Australia, Report No. 07/06, National Urban Water Governance Program, Monash University, 2007.

[20] Sahely, H., Kennedy, C. \& Adams, B., Developing sustainability criteria for urban infrastructure systems. Canadian Journal of Civil Engineering, 32(1), pp. 72-85, 2005. doi: http:// dx.doi.org/10.1139/104-072

[21] Bolger, R., Monsma, D. \& Nelson. R., Sustainable Water Systems: Step One—Redefining the Nation's Infrastructure Challenge, A report of the Aspen Institute's Dialogue on Sustainable Water Infrastructure in the U.S., May 2009.

[22] Apostolidis, N., Hertle, C. \& Young, R., Water recycling in Australia. Water, 3, pp. 869-881, 2011. doi: http://dx.doi.org/10.3390/w3030869

[23] Mitchell, V.G., Applying integrated urban water management concepts: a review of Australian experience. Environ. Manag., 37(5), pp. 589-605, 2006. doi: http://dx.doi.org/10.1007/ s00267-004-0252-1

[24] Hurlimann, A. \& Dolnicar, S., When public opposition defeats alternative water projects-the case of Toowoomba, Australia. Water Research, 44(1), pp. 287-297, 2010. doi: http://dx.doi. org/10.1016/j.watres.2009.09.020

[25] Robèrt, K.H., Schmidt-Bleek, B., Aloisi de Larderel, J., Basile, G., Jansen, J.L., Kuehr, R., Price Thomas, P., Suzuki, M., Hawken, P. \& Wackernagel, M., Strategic sustainable development—selection, design and synergies of applied tools. Journal of Cleaner Production, 10(3), pp. 197-214, 2002. doi: http://dx.doi.org/10.1016/s0959-6526(01)00061-0

[26] Pearson, L.J., Coggan, A., Proctor, W. \& Smith, T.F., A sustainable decision support framework for urban water management. Water Resources Management, 24(2), pp. 363-376, 2010.

[27] Saaty, T.L., Decision making with the analytic hierarchy process. International Journal of Services Sciences, 1(1), pp. 83-98, 2008. doi: http://dx.doi.org/10.1504/IJSSCI.2008.017590

[28] American Institute of Chemical Engineers' Center for Waste Reduction Technologies (AIChE CWRT), Total Cost Assessment Methodology, AIChE: New York, NY, 1999.

[29] Brink, C. \& van Grinsven, H., Costs and benefits of nitrogen in the environment. The European Nitrogen Assessment, ed. M.A. Sutton, C.M. Howard, J.W. Erisman, G. Billen, A. Bleeker, P. Grennfelt, H. van Grinsven \& B. Grizzetti, Cambridge University Press, pp. 513-540, 2011.

[30] Birch, M.B.L., Gramig, B.M., Moomaw, W.R., Doering, O.C., III \& Reeling, C.J., Why metrics matter: evaluating policy choices for reactive nitrogen in the Chesapeake Bay watershed. Environmental Science and Technology, 45 (1), pp. 168-174, 2011. doi: http://dx.doi. org/10.1021/es101472z

[31] Compton, J.E., Harrison, J.A., Dennis, R.L., Greaver, T.L., Hill, B.H., Jordan, S.J., Walker, H. \& Campbell, H.V., Ecosystem services altered by human changes in the nitrogen cycle: a new perspective for US decision making. Ecology Letters, 14, pp. 804-815, 2011. doi: http://dx.doi. org/10.1111/j.1461-0248.2011.01631.x

[32] Katie Steele, K., Carmel, Y., Cross, J. \& Wilcox, C., Uses and misuses of multicriteria decision analysis (MCDA) in environmental decision making. Risk Analysis, 29 (1), pp. 26-33, 2009. doi: http://dx.doi.org/10.1111/j.1539-6924.2008.01130.x 
[33] Hämäläinen, R.P. \& Alaja, S., The threat of weighting biases in environmental decision analysis. Ecological Economics, 68 (1-2), pp. 556-569, 2008. doi: http://dx.doi.org/10.1016/j. ecolecon.2008.05.025

[34] Rowley, H.V., Peters, G.M, Sven Lundie, S. \& Moore, S.J., Aggregating sustainability indicators: beyond the weighted sum. Journal of Environmental Management, 111, pp. 24-33, 2012. doi: http://dx.doi.org/10.1016/j.jenvman.2012.05.004

[35] Department of Climate Change, National Greenhouse Accounts (NGA) Factors. Updating and replacing the AGO Factors and Methods Workbook, Commonwealth of Australia, January 2008.

[36] Daniels, P., Porter, M., Bodsworth, P. \& Coleman, S., Externalities in Sustainable Regional Water Strategies: A Compendium of Externality Impacts and Valuations, Urban Water Security Research Alliance Technical Report No. 42, 2012.

[37] European Commission, External Costs, Research results on socio-environmental damages due to electricity and transport (EUR 20198), Office for Official Publications of the European Communities: Luxembourg, p. 14, 2003.

[38] Plant, R., Herriman, J. \& Atherton, A., The Full Spectrum of Costs and Benefits: Valuing Melbourne's Urban Water Externalities, Discussion Paper Prepared for the Victorian Smart Water Fund by the Institute for Sustainable Futures, Sydney, 12 April, 2007 (Final).

[39] Government of Western Australia, Securing Our Water Future: A State Water Strategy for Western Australia, 2003. 